\title{
ÁREAS PROTEGIDAS E AMBIENTES URBANOS: NOVOS SIGNIFICADOS E TRANSFORMAÇÕES ASSOCIADOS AO FENÔMENO DA URBANIZAÇÃO EXTENSIVA
}

\section{Protected Areas and Urban Environments: new meanings and changes associated with the phenomenon of extensive urbanization}

\author{
Altair Sancho \\ Universidade Federal de Juiz de Fora, Juiz de Fora, Minas Gerais, Brasil \\ altairsancho@hotmail.com \\ José Antonio Souza de Deus \\ Universidade Federal de Minas Gerais, Belo Horizonte, Minas Gerais, Brasil \\ jantoniosdeus@uol.com.br
}

Artigo recebido em 22/08/2014 e aceito para publicação em 08/07/2015

RESUMO: Este trabalho propõe-se a discutir a relação entre ações de proteção da natureza e ambientes urbanos, com um olhar atento para as influências do fenômeno da urbanização extensiva na dinâmica de territórios permeados por áreas protegidas. Postula-se que esse interrelacionamento não remete apenas à origem do movimento em prol da criação de espaços de conservação da natureza, mas interfere inclusive em sua constituição, principalmente em países como o Brasil, onde muitas dessas áreas foram implantadas nas proximidades de centros urbanos. Diante das novas configurações socioespaciais e organizacionais presenciadas nas metrópoles nas últimas décadas, chamamos a atenção para o fenômeno da urbanização extensiva, termo cunhado por Monte-Mór para interpretar o movimento de extensão das condições e modos de vida urbanos para além dos limites das metrópoles. O caráter unificador desse movimento e as pressões exercidas na fronteira têm sido responsáveis por ressignificar a relação rural e urbano, em sentido amplo, com desdobramentos diretos na dinâmica territorial de áreas protegidas localizadas na zona de abrangência de centros metropolitanos. Como resultado, percebe-se uma complexificação dos sentidos e significados atribuídos às áreas protegidas e o nascimento de inúmeros desafios aos propósitos de conservação da biodiversidade e promoção de desenvolvimento territorial.

Palavras-chave: Áreas Protegidas. Urbanização Extensiva. Ordenamento Territorial.

ABSTRACT: This paper proposes to discuss the relationship between actions of nature protection and urban environments, with attention to the influences of the phenomenon of extensive urbanization in the dynamics of territories permeated by protected areas. It is postulated that this interrelationship not only refers to the origin of the movement to create spaces for nature conservation, but also interferes in its constitution, especially in countries like Brazil, where many of these areas were implanted near urban centers. Faced with the new socio-spatial and organizational configurations observed in the metropolis in recent decades, we call attention to the phenomenon of extensive urbanization, a term proposed by Monte-Mór to interpret the movement of extension conditions and urban ways of life beyond the limits of the metropolis. The 
unifying character of this movement and the pressures on the border has been responsible for reframing the rural-urban relationship, broadly, with direct repercussions on territorial dynamics of protected areas located in the coverage of metropolitan centers. As a result, there is a complexity of the senses and meanings attributed to protected areas and the appearance of several challenges to the purposes of biodiversity conservation and promotion of territorial development.

Keywords: Protected Areas. Extensive Urbanization. Territorial Planning.

\section{INTRODUÇÃO}

O processo de criação e gestão de territórios dedicados à conservação de atributos naturais representa um fenômeno de grande complexidade na atualidade, envolvendo não apenas aspectos associados à conservação de atributos naturais, mas também, aspectos socioculturais, políticos e econômicos. Resultado de uma relação historicamente caracterizada pela tentativa de dominação da natureza pela sociedade (e mais especificamente a sociedade ocidental, ancorada na perspectiva hegemônica do pensamento racional e científico, responsável por sustentar o advento e supervalorização da técnica e que acabou solidificando um sentido de natureza cada vez mais instrumental e funcional), o estabelecimento de espaços naturais protegidos passou a constituir, sobretudo no século XX, um elemento de reordenamento territorial, com profundas implicações nas dinâmicas socioespaciais onde são implementados.

Num primeiro momento, a origem desse movimento esteve associada à consolidação do capitalismo em âmbito mundial, sob a égide do modelo urbano-industrial da civilização ocidental. A hegemonia da cidade enquanto forma de organização social, mais complexa e distante dos valores e formas de vida rural, ocasionou a migração maciça das populações para os centros urbanos e transformou a maneira como os homens se relacionavam e concebiam a natureza, ocorrendo, em última instância, um amplo processo de desnaturalização da sociedade (MORAES e COSTA, 1984). A concepção de natureza-mercadoria, sustentáculo do crescimento econômico à época, levou à intensificação do processo de transformação e consumo dos atributos naturais e, por consequência, contribuiu para o aumento significativo das taxas de degradação ambiental, sobretudo a partir do final do século XIX e início do século XX. Nesse período, os espaços protegidos já representavam uma oportunidade de retorno às origens e uma opção de lazer para as populações das cidades, haja visto o contexto de deterioração das condições urbanas então existentes na maioria das metrópoles.

$\mathrm{Na}$ segunda metade do século XX, a constatação de que o ritmo acelerado do consumo de atributos naturais já representava a diminuição e, até o esgotamento de estoques de alguns bens nãorenováveis, introduziu, no debate político, a ideia de limites ao crescimento, cujos desdobramentos deram início a um processo de politização do meio ambiente (BRYANT e BAILEY, 1997) e levaram à construção de uma agenda ambiental global, temas aliás exaustivamente debatidos pela academia. É relevante salientar que, no âmbito dessa agenda, a criação de áreas naturais protegidas passou a adquirir importância estratégica, seja como um dos instrumentos de imposição dessa nova ordem ambiental, seja pelos novos significados e objetivos - materiais e simbólicos - a ela associados.

Muitos desses objetivos, a nosso ver, podem ser interpretados a partir de uma perspectiva cada vez mais inter-relacionada ao modo de vida urbano, já que, na atualidade, as áreas protegidas desempenham o papel de reservas energéticas, laboratórios de pesquisa e educação ambiental e estratégia para garantia de qualidade ambiental nos ambientes urbanos (fornecimento de água, espaços verdes, qualidade do ar, entre outros), além das funções já tradicionalmente conhecidas, como conservação da biodiversidade, local de descanso e lazer ou produção florestal, etc..

Inspirado por esses novos sentidos ou significados associados às áreas protegidas, o presente ensaio tem o objetivo de construir uma problematização sobre a relação entre as ações de proteção da natureza e os ambientes urbanos, sobretudo quando consideramos as novas configurações socioespaciais e organizacionais das metrópoles e 
suas respectivas influências em âmbito regional, abrangendo aí, muitos territórios de áreas protegidas. Nossa tese é que, hoje, uma interpretação crítica sobre esse instrumento de ordenamento territorial do Estado passa, necessariamente, pelo reconhecimento da existência de uma relação cada vez mais indissociável entre essas duas dimensões da realidade. Tal perspectiva, a nosso ver, não se relaciona apenas à origem do movimento em prol da criação de espaços de conservação da natureza, mas corresponde a um dos elementos presentes em sua criação/constituição, principalmente em países como o Brasil, onde muitas dessas áreas foram implantadas nas proximidades de centros urbanos.

Nesses casos, é possível verificar, nas últimas décadas, inúmeras transformações e novos desafios à conservação da natureza associados, em grande medida, ao fenômeno que Monte-Mór (2006) denominou urbanização extensiva. Trata-se de um movimento crescente de extensão das condições e modos de vida urbanos para além das cidades, observado em grande parte das metrópoles brasileiras. Cada vez mais fragmentada, a metrópole deixa de constituir nesse contexto o ponto culminante das culturas locais, assumindo uma tendência de espraiamento, que conformam novas relações com sua área de abrangência. Por consequência, a separação entre rural e urbano deixa de ser tão nítida e essa relação se ressignifica, de maneira intensa e complexa. As áreas rurais, antes sinônimos de atraso, passam, nessa perspectiva, a integrar a zona simbólica ampliada das metrópoles (CHAMBERS, 1990; Soja, 2008), cumprindo novos papéis à reprodução do Capital. Novamente, a ideia de retorno às origens ganha centralidade frente ao caos instalado nas cidades. O contato com a natureza e a vivência de elementos da ruralidade são resgatados e redimensionados por meio do desenvolvimento de atividades econômicas como o turismo e o setor imobiliário, que são responsáveis por provocar alterações expressivas nos processos socioespaciais do meio rural, incluindo-se aí, influências diretas na dinâmica territorial das áreas protegidas, contexto que tem gerado novos desafios ao propósito da conservação da natureza.

Nosso argumento sobre essa indissociável relação entre ambientes urbanos e áreas protegidas ganha mais sustentação quando reconhecemos que vivemos em um tempo de espaços mais fragmentados, economia mais flexível e "deslocalizada", Estados mais fragilizados e identidades mais instáveis e fluidas, o que implica considerar novas experiências de tempo e espaço, como salienta Haesbaert (2006), fazendo alusão ao conceito cunhado por Harvey (1989). Nesse cenário, as concepções de território são ressignificadas em virtude de novos referenciais espaciais e identitários que passam a caracterizar e moldar as experiências cotidianas e também a atuação de Estados, empresas e representatividades sociais. Os territórios são cada vez mais permeados por novos interesses, sujeitos e arranjos territoriais, tanto internos quanto externos, que se interconectam por meio de redes, numa perspectiva multiescalar, relativizando, assim, os sentidos de fronteira e de limite territorial. É nessa perspectiva que as pesquisas sobre áreas protegidas se deparam com o desafio de reconhecer e melhor compreender esse movimento. Tal propósito exige, então, que se considere a existência e influência de inúmeras forças atuantes na conformação desses territórios, entre as quais, aquelas associadas a forças e interesses exógenos, notadamente vinculados à manutenção ou extensão das condições e modo de vida urbanos.

Vale dizer que tal proposta de reflexão é de natureza essencialmente teórica e envolveu diálogos conceituais com autores que se dedicam a temas como relação sociedade e natureza, áreas protegidas e espaço urbano. Tais debates são inspirados em uma pesquisa de doutorado em andamento, cujo objetivo central reside em compreender o processo de ordenamento territorial associado à criação e gestão de duas unidades de conservação localizadas na região central de Minas Gerais: o Parque Nacional da Serra do Cipó e a Área de Proteção Ambiental Morro da Pedreira.

\section{Areas Protegidas: movimento com raízes urbanas?}

Quais seriam as raízes do movimento em prol da proteção da natureza, que culminaram com a adoção, em âmbito mundial, de estratégias de criação de espaços institucionalmente protegidos? Que caminho trilhar no intuito de tecer uma compreensão crítica sobre os significados desse fenômeno, na 
contemporaneidade? Um caminho sugerido para a reflexão implicaria em priorizar a estreita relação existente entre as áreas protegidas e os ambientes urbanos a respeito de tais questões, numa perspectiva dialética.

Evidentemente, quando nos propomos a responder a tais questões, não podemos desconsiderar, conforme indica Medeiros (2003), que a criação de regimes especiais de proteção de recortes territoriais em função de seus atributos naturais é uma prática antiga, surgida ainda na Idade Média, inicialmente com o objetivo de resguardar espécies da fauna para o exercício da caça pela realeza e aristocracia rural. Com o passar do tempo, outros aspectos e interesses foram sendo internalizados à temática da proteção. Residia nessa época, segundo o autor, uma perspectiva de natureza exterior e a serviço do homem, percepção construída e disseminada por uma visão antropocêntrica.

Mas, como enfatizado, pretendemos priorizar nesta discussão a relação intrínseca entre práticas conservacionistas e o modo de vida urbano. Para tanto, propomos uma reflexão sobre o papel e os significados assumidos pelas áreas protegidas no contexto de modernidade e de consolidação da civilização urbano-industrial, com um olhar atento às novas configurações socioespaciais observadas nas metrópoles, nas últimas décadas, e suas implicações na dinâmica territorial de áreas protegidas localizadas em sua área de abrangência.

Quando a cidade deixou de constituir apenas espaço político (momento em que concentrava uma superestrutura de poder deslocada da produção e da infraestrutura econômica, até então reunidos no meio rural), e passou a constituir espaço de realização da produção, da acumulação e do excedente (com a "entrada" do mercado e, posteriormente, da indústria na cidade), ela se tornou cada vez mais subordinada à lógica do Capital. E com a consolidação da cidade enquanto lócus do projeto modernizador, as relações entre cidade e campo, trabalho intelectual e manual, sociedade e natureza, foram profundamente ressignificadas (LEFEBVRE, 1986; HARVEY, 1982, 1993; MONTE-MÓR, 2006, 1994; SOJA, 2008).

$O$ advento da cidade industrial (marco da

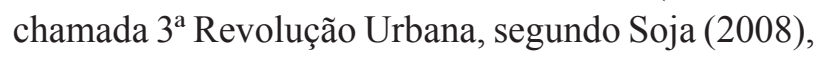

provocou um intenso processo de deslocamento da população para as áreas urbanas, atraídas pelo ideário da cidade enquanto espaço de libertação da hegemonia do "velho dominador": a oligarquia, proprietária de terras. É nesse contexto que o modo de vida das cidades passou a representar a imagem do novo, do moderno e do melhor, numa visão alicerçada na dicotomia entre urbano e rural, visão essa que, segundo Monte-Mor (2006, p.66), "informou as percepções da cidade e do processo de modernização da sociedade por várias décadas". Com o ingresso dessa leva de trabalhadores nas cidades, houve uma enorme expansão das áreas metropolitanas e a consequente percepção da deterioração das condições urbanas, sobretudo, sanitárias, de moradia e transporte. Essa crise da metrópole industrial está na origem das primeiras intervenções urbanas com caráter científico.

Nesse contexto, adquire destaque a abordagem adotada pelo Barão Georges-Eugène Haussmann, em Paris, cujo modelo de reestruturação urbana veio a influenciar todo o mundo ocidental. Segundo Monte-Mór (2006), considerado o primeiro plano regulador para uma metrópole moderna, sua proposta privilegiou um esquema de racionalidade urbanística, com forte intervenção do Estado, envolvendo preocupações higienistas que justificaram a demolição de áreas e edificações degradadas, construção de casas, implantação de infraestruturas urbanas e parques, abrindo grandes avenidas e dando à área central da cidade um sentido majestoso. No Brasil, em capitais como Belo Horizonte, Manaus, Belém, São Paulo e Rio de Janeiro, esses princípios foram adotados por engenheiros como Saturnino de Brito, Pereira Passos e Prestes Maia em iniciativas de reformas urbanas. Vale ressaltar que, além do importante papel desse modelo de intervenção nas cidades idealizado por Haussmann,

as influências que se seguem no Brasil a partir do século XX são extremamente variadas e múltiplas em seus princípios, ora privilegiando aspectos racionais da ação individual articulados com o sentido de progresso, como nas propostas de Le Corbusier, ora articulados com o resgate 
do sentido de comunidade e de cultura das cidades, como em Sitte e nas propostas de cidades-jardim de Ebenezer Howard. Além dessas duas correntes mais influentes, que Choay (2000) chamou 'progressista' e 'culturalista', outras podem ser identificados, como o 'naturalismo' norte-americano de Frank Lloyd Wright, herdeiro da tradição jeffersoniana, ou o 'organicismo' do biólogo Patrick Geddes (MONTE-MÓR, 2006, p.03).

No Brasil, sem desconsiderar a presença de muitas dessas correntes urbanísticas, é preciso reconhecer a predominância da vertente progressista, capitaneada por Le Corbusier, que consolida um modelo de regulação urbanística que sustenta o processo de modernização do espaço urbano no país, necessário ao estabelecimento das condições gerais de produção capitalista em sua fase industrial), cujos esforços estavam concentrados na melhoria da qualidade de vida das cidades, reunindo, entre outros, projetos de parques e áreas verdes (MONTE-MÓR, 2006).

Essas áreas verdes e, em especial, aquelas localizadas fora dos grandes centros, passaram a significar então a possibilidade do homem moderno de refazer suas energias gastas na vida estressante das cidades e do trabalho monótono, enquanto espaços de recreação e descanso. Para Thomas (THOMAS, 1983 apud DIEGUES, 2004), o crescimento populacional, principalmente nas cidades inglesas, teria inclusive influenciado o surgimento de certo sentimento antissocial ou anti-agregativo, originando uma atitude de contemplação da natureza selvagem, lugar de reflexão e de isolamento espiritual. Corbin (CORBIN, 1989 apud DIEGUES, 2004) ressalta também o papel dos escritores românticos do século XIX na valorização do mundo natural: "estes fizeram da procura do que restava de natureza selvagem, na Europa, o lugar da descoberta da alma humana, do imaginário do paraíso perdido, da inocência infantil, do refúgio e da intimidade, da beleza e do sublime" (CORBIN, 1989, p.24).

Percebemos aí já um sentimento de recusa e de contestação do modo de vida nas cidades - sentimento esse que, num primeiro momento, estava restrito às classes política e intelectual - que pode ser interpretado, em última instância, como a recusa do próprio homem: o homem moderno, cujas relações sociais nas cidades estavam cada vez mais condicionadas pelo pensamento mecanicista e racional e por valores individualistas, regulados pelo mercado e pelo ritmo das fábricas. Ocorreu, de certa forma, uma tentativa de inversão dos sentidos atribuídos à natureza, pelo menos para uma pequena elite intelectual e política que começava a questionar esse modo de vida nas cidades. Um movimento de exaltação do "mundo natural" - que até então era, ao contrário, reconhecido como irracional, selvagem, inferior - procurou resgatar, então, sentimentos e valores característicos de modos de vida que possuíam maior proximidade da natureza: liberdade, prazer, descanso, lentidão, ócio, beleza, imaginação...

Vale ressaltar que essa perspectiva de exaltação e de retorno à natureza, capitaneada pelas classes mais abastadas e por escritores e visionários da época, é que justificou as primeiras iniciativas de proteção nos Estados Unidos - tema exaustivamente debatido pela literatura especializada -, cujo ideário de conservação influenciou diretamente as ações subsequentes em todo o mundo. Ainda no século XIX, foi criada nos EUA a concepção de parque nacional enquanto espaço natural, selvagem (wilderness), sob a égide do mito do paraíso perdido (DIEGUES, 2004), representado por grandes áreas pretensamente não-habitadas, principalmente após o extermínio de populações indígenas antes aí domiciliadas e a expansão da fronteira para o oeste. É importante assinalar, portanto, que nesse período, em que o capitalismo norte-americano já estava consolidado e a urbanização do país era acelerada, a criação de áreas protegidas se justificou, sobretudo, para fins estéticos e recreacionais, tendo sido elas colocadas à disposição das populações urbanas (DIEGUES, 2004).

Ainda segundo Diegues (2004), no início e meados do século XIX, houve nos EUA uma corrida para o Oeste (decreto Homestead Act), estratégia essa ancorada na ideia de um território praticamente "selvagem" em termos de alteração humana e que precisava ser colonizado. Contudo, com o rápido crescimento do processo de transformação da natureza, associado à agricultura e expansão da 
indústria, emergiu uma discussão sobre os custos ambientais e sociais dessa política (que inclusive levou o Census Bureau americano a decretar o fechamento da fronteira para novas expansões agrícolas). E, como resultado, somaram-se às justificativas estéticas de conservação, justificativas de eficiência do uso e acesso dos atributos naturais e de equidade nessa utilização. O sentido atribuído à relação homem e natureza nesse caso preconizava a continuidade do uso de atributos naturais, desde que realizada de maneira racional e para o bem da maioria dos cidadãos, consolidando uma vertente econômica da conservação e abrindo espaço para o debate sobre a democracia no acesso a esses recursos.

Outra corrente ambientalista - o movimento preservacionista norte-americano - rebateu essa lógica de proteção da natureza que preconizava que os atributos naturais devessem sustentar o progresso do país, mesmo que de forma controlada. Esse movimento foi muito influenciado pelas ideias da corrente científica da História Natural - em especial pela teoria da evolução (Charles Darwin) - e pelo surgimento da ecologia e da noção de ecossistema. Os adeptos da preservação eram contrários a essa visão utilitarista da natureza e à postura destrutiva e consumista do homem (visão essa que iria representar a base para o movimento ambientalista nos anos de 1960 e 1970). O fortalecimento dessa corrente de pensamento foi, inclusive, responsável por reconfigurar o modelo de proteção da natureza nos EUA, que passou a adotar, a partir das primeiras décadas do século XX, critérios ecológicos e não mais estéticos, para a criação de unidades de conservação, perspectiva que foi reproduzida em inúmeros países, inclusive no Brasil.

Medeiros (2003) chama atenção ainda para o movimento europeu nesse período (pouco lembrado em pesquisas sobre áreas protegidas), cujos debates sobre a proteção da natureza estavam concentrados em propostas de proteção de paisagens, reconhecidas como atributos de beleza cênica e testemunhos de práticas socioculturais ancestrais de uso do solo, isso porque, em território europeu, dificilmente poderia se fazer alusão a espaços "intocados" devido ao alto grau de antropização de suas paisagens/territórios.

Percebemos, portanto, que já nas primeiras discussões sobre objetivos e justificativas associados à criação de áreas protegidas a relação de proximidade ao modo de vida urbano-industrial estava muito presente, de forma direta ou indireta. É importante ressaltar, por exemplo, que os espaços de decisão estavam, desde então, precipuamente concentrados nas cidades e os rumos do debate eram definidos no âmbito da esfera pública (Estado), com apoio da academia e de alguns segmentos ambientalistas da sociedade. Portanto, já naquela época, prevalecia uma lógica externa às realidades onde tais áreas protegidas eram criadas, norteada por referenciais culturais particulares e muito distantes da dinâmica socioespacial onde estavam localizadas, notadamente em espaços rurais.

No decorrer da evolução desse processo, é possível reconhecer, portanto, que essa estreita relação entre as cidades e as áreas protegidas não esteve presente apenas na origem do movimento em prol da criação de espaços de conservação da natureza, mas vem sendo um de seus elementos constituintes. Nosso argumento é de que os diversos significados atribuídos às áreas protegidas transformaram-se e ainda se modificam conforme as mudanças nos processos de organização da sociedade, especialmente quando consideramos as transformações presenciadas nos espaços urbanos a partirdas décadas de 1970/1980.Apartirdesseperíodo, segundo Soja (2008), a reestruturação do modelo capitalista de produção, agora baseada em um regime de acumulação flexível pós-fordista e na revolução tecnológica, e a crescente globalização do capital, do trabalho e da cultura, possibilitada pelas novas redes transnacionais e informacionais, foram responsáveis por acarretar novas reconfigurações socioespaciais nas metrópoles, como por exemplo: urbanização extensiva e dispersa, globalização econômica e cultural da paisagem urbana, privatização do espaço público, surgimento de novas formas de polarização socioespacial e a crescente transformação da vida urbana em simulacro (TONUCCI FILHO, 2009).

No âmbito desse amplo e complexo processo de reestruturação do espaço urbano, gostaríamos de chamar a atenção para uma perspectiva de investigação que busca reconhecer e compreender, mais detidamente, o movimento de extensão das 
condições urbanas para além dos limites das cidades, examinando suas influências na dinâmica de territórios permeados por áreas protegidas.

\section{A extensão do urbano e a imposição de novas condicionantes aos territórios permeados por áreas protegidas.}

Com a globalização do Capital e do trabalho e os novos processos de produção verificados a partir das décadas de 1970/1980, novas configurações socioespaciais passaram a ser percebidas nos centros urbanos, em especial nas áreas metropolitanas, influenciando a relação entre o urbano e o rural, a cidade e o campo, conferindo, por consequência, novos sentidos às áreas protegidas localizadas em sua área de abrangência e transformando seu papel enquanto instrumento de ordenamento territorial do Estado. Soja (2008, p.285) afirma que:

los flujos globales de inversión de capital, la migración de trabajadores, de información e innovación tecnológica están remodelando el espacio urbano y las relaciones locales entre el capital y el trabajo, creando nuevos espacios industriales, una reorganización de las identidades de clase, nuevas divisiones urbanas respecto del trabajo y un patrón de estratificación social y espacial polarizado y refragmentado (SOJA, 2008, p.285).

Em consequência, ficou cada vez mais difícil perceber os limites do espaço urbano nas grandes metrópoles, realidade que inspirou esse autor a propor o conceito de pós-metrópole. A pósmetrópole representaria um caminho de interpretação desse novo cenário de reconfiguração territorial em curso nas metrópoles mundiais e dos novos padrões e especificidades da forma, função e comportamento urbanos, bem como da nova ordem social urbana e novos padrões de estratificação social e desigualdade socioeconômica, intimamente associados à globalização e à reestruturação econômica pós-fordista.

A exopolização é um dos "discursos contemporâneos" adotados por Soja para compreender a pós-metrópole: "uma extensão do urbanismo moderno e modernista, uma metamorfose ainda parcial e incompleta que sempre levará consigo restos dos espaços urbanos periféricos" (SOJA, 2008, p.218). Nessa metamorfose, as cidades tenderiam a representar cada vez menos o ponto culminante das culturas locais e territoriais, uma qualidade intrínseca da urbanidade presente nas cidades. Pois a cidade contemporânea parece estar cada vez menos vinculada a sua especificidade espacial, enquanto ponto fixo de referência, memória e identidade coletiva. A metrópole, cada vez mais fragmentada, passa a se esparramar, reestruturando-se a partir de inúmeras polaridades e centralidades de características múltiplas, com inúmeras consequências nas relações socioespaciais, em sentido amplo.

Como resultado desse movimento de "exopolização" das metrópoles, Soja (2008) reconheceu também um processo de desconstrução da antiga divisão conceitual entre cidade e região, num sentido de uma recombinação dessa relação. Esse processo leva as metrópoles a adquirir a forma e o conteúdo de "cidade-região", enquanto rede de nós urbanos, unidos de forma conjunta em um sistema definido regionalmente, que compreende cidades, subúrbios, povos, aldeias, zonas selvagens, incluindose aí, as áreas protegidas.

É nesse sentido que essa nova configuração socioespacial das metrópoles vai interferir diretamente na dinâmica territorial de áreas protegidas localizadas em sua zona de abrangência, que passam a conviver, cada vez mais, com lógicas e situações antes mais características dos ambientes urbanos: maior fluxo e concentração de pessoas, conflitos sobre o uso e ocupação do solo, zoneamento territorial, especulação imobiliária, aumento de demandas por serviços urbanos diversos, incremento de atividades como turismo, entre outros. Essa nova lógica socioespacial passa a representar uma complexificação dos sentidos e propósitos de conservação associados às áreas protegidas.

É relevante assinalar que essa tendência de expansão e derramamento da metrópole, interpretada por Soja a partir de sua análise da cidade de Los Angeles (EUA), foi também analisada no contexto brasileiro. Monte-Mór (2005), durante uma pesquisa 
na Amazônia brasileira, verificou que as condições de produção industrial, antes concentradas nas regiões metropolitanas e cidades monoindustriais, se encontravam em um movimento crescente de espraiamento e extensão para regiões distantes das áreas urbanas (processo chamado por ele de urbanização extensiva), num movimento dialético centro urbano-tecido urbano. O tecido urbano é compreendido pelo autor como a "trama de relações socioespaciais que se estende à região resultante da explosão da cidade preexistente, evidenciando uma dilatação da forma de organização e produção industrial para o campo" (MONTE-MÓR, 1994, p.170).

Evidentemente, é preciso ponderar que esse fenômeno não alcança, pelo menos no caso brasileiro, um sentido totalizante, sobretudo quando se considera que determinadas teorias sobre o urbano são desenvolvidas a partir da análise de realidades exógenas e específicas, como a europeia e a norte-americana. Sem deixar de considerar a força desse movimento de extensão e capilarização do urbano, ainda é possível encontrar no espaço rural brasileiro um significativo número de grupos sociais (camponeses e agricultores familiares, quilombolas, povos indígenas, ribeirinhos, entre outros) que não estão totalmente permeados por essa lógica urbanoindustrial. Esses grupos estão localizados, em geral, próximos à "fronteira", mesmo que já se perceba, em alguns deles, traços do projeto moderno no cotidiano (presença do Estado, inserção incipiente no mercado, etc.).

De qualquer forma, é inevitável reconhecer que essa extensão das relações socioespaciais para além das metrópoles tem implicado em um processo de ressignificação da relação urbano e rural, agora mais intensa e complexa. O espaço rural, que antigamente era facilmente identificável como separado da área urbana, com uma imagem associada ao atraso, agora, com a extensão do tecido urbano, se torna zona simbólica (Soja, 2008), cumprindo novos papéis, sendo "reproducidos de forma indiscriminada como signos y horizontes potenciales dentro de uma topografia comum" (CHAMBERS, 1990, p.54). Ainda segundo Chambers, a antiga separación entre un exterior 'natural' obvio y un interior urbano 'artifical' se debilita y tende a colapsarse (...) lo que alguna vez constituyó claramente para la ciudad otro lugar, ahora está entrando en su zona simbólica ampliada (CHAMBERS, 1990, p.53).

Assim, se antes era possível identificar e diferenciar com certa facilidade áreas urbanas de áreas rurais, em termos de presença de materialidades, lógicas de produção, consumo e comercialização, modos de vida, visões sobre a natureza, hoje essa separação ficou mais tênue, mais fluida. Antes consideradas distantes do ideal de vida moderno (leia-se: sinônimo de cidade e todas as suas facilidades e vantagens associadas) e de baixo valor em termos do mercado de terras, as regiões caracteristicamente rurais, sobretudo aquelas próximas aos grandes centros urbanos, passam a ser "reinventadas" por um novo urbanismo que, em associação com o capital imobiliário, vende uma utopia urbana (Soja, 2008) para a população das grandes cidades. É nesse contexto que campanhas de marketing de condomínios e loteamentos rurais veiculam a ideia de retorno ao passado e à natureza, oportunidade de viver melhor, com mais qualidade de vida e segurança, distante do caos e da violência que assolam os centros urbanos na contemporaneidade.

Nesse movimento, os espaços naturais protegidos situados na área de influência desses grandes centros urbanos passam a integrar cada vez mais sua zona simbólica ampliada, adquirindo novos papéis e significados. Sua função de espaço de contemplação e lazer para as populações residentes nas cidades é amplificada, em virtude desse caos urbano que se instala nas metrópoles, da própria relevância assumida pela questão ambiental na atualidade e das novas tendências do mercado ecológico, que enfatizam a importância da adoção de hábitos mais próximos à natureza. Como exemplo, podemos citar o número cada vez maior de pessoas que visitam parques naturais em finais de semana, feriados prolongados e períodos de férias. De acordo com dados divulgados em 2014, pelo Instituto Estadual de Florestas e Instituto Chico Mendes de Conservação da Biodiversidade (ICMBio), somente 
o número de visitantes aos parques naturais de Minas Gerais aumentou de 274 mil, em 2012, para 305 mil, em 2013, aumento decorrente de um interesse crescente dos turistas por redutos de fauna e flora. E como resultado desse interesse, os governos tem direcionado novos investimentos para ações de promoção e de implantação e/ou incremento de estruturas de uso público, voltadas ao atendimento dos visitantes.

Evidentemente, o aumento desse fluxo de pessoas estimula o crescimento da cadeia produtiva associada, direta e indiretamente, aos parques e demais áreas naturais, em especial a do turismo. Novas oportunidades de negócio são aí criadas, ocorre o aumento das vagas de trabalho e emprego, a atração de investimentos e, consequentemente, o incremento populacional. Ao mesmo tempo, muitos vilarejos e distritos localizados próximos a áreas protegidas passam a experimentar inúmeras transformações nos modos de vida, intensificadas pela chegada e pelo contato com forasteiros e visitantes, que geram alterações das relações de sociabilidade, nos hábitos culturais e de consumo, nas temporalidades, na relação com a terra e com o dinheiro, nos métodos produtivos e na relação patrão-empregado, em alguns casos, desencadeando processos de desterritorialização. Além disso, até então pacatos e seguros, tais lugares começam a conviver com problemas sociais e espaciais antes apenas existentes em centros urbanos: roubos, violência, tráfico e consumo de drogas, congestionamentos, excesso de lixo, poluição visual e sonora, inflação, especulação imobiliária, entre outros.

Abusca porcasas de campo everaneio também cresce nesse contexto, em grande medida estimulada por essa proximidade das áreas protegidas dos centros urbanos. A existência de grandes áreas preservadas, com caráter "selvagem e intocado", estimula, nesse contexto, o mercado de turismo de segunda residência em suas proximidades, agregando valor aos novos empreendimentos imobiliários. Em contrapartida, o valor da terra se eleva, acirram-se os danos ao meio ambiente natural e surgem novas demandas por serviços públicos, exigindo das prefeituras maior capacidade técnica para a gestão desse território. $\mathrm{O}$ poder público se vê, então, diante da necessidade de dotar o território de novas infraestruturas para comportar o acelerado incremento de pessoas e serviços, com significativos impactos sobre o ambiente natural. Gradativamente, as paisagens, antes caracteristicamente rurais, passam a incorporar novas materialidades urbanas. Como resultado desse processo, tensões e conflitos associados ao uso e ocupação do solo se multiplicam, com influências diretas nas configurações socioespaciais dessas localidades e na complexificação dos propósitos de conservação da natureza.

Os corpos técnicos das áreas protegidas, por sua vez, passam a enfrentar inúmeros desafios em termos de gestão territorial e garantia do cumprimento dos objetivos da unidade de conservação. Pois além de atribuições específicas (administração, fiscalização, manejo, uso público, prevenção contra incêndios, entre outras), a gestão de uma área protegida passa, a partir daí, a envolver também ações constantes de aproximação e interlocução com diferentes segmentos sociais.

Essas condicionantes recentes que se impõem à realidade de muitas áreas protegidas tem motivado alguns pesquisadores a tentar melhor compreender os novos significados que se concretizam em virtude dessa relação de maior proximidade aos centros urbanos.

O caso da região da Serra do Cipó, em Minas Gerais, é emblemático nesse sentido. Caminho para o Arraial de Tejuco (atual Diamantina), a região foi ocupada desde o século XVII, mas somente a partir dos anos de 1970 tem início um processo de transformações mais significativas, aí associadas, em grande medida, ao incremento do turismo ecológico. Com a pavimentação da rodovia MG-010, o acesso à região foi facilitado e contribuiu para o aumento do fluxo de pessoas, sobretudo oriundas da região metropolitana de Belo Horizonte, sendo percebidas novos e, muitas vezes, conflitantes interesses em relação aos usos do solo e dos atributos naturais.

A rica biodiversidade, $\mathrm{o}$ alto endemismo de suas espécies, o potencial hídrico e a relevância paisagística dessa região, associadas às crescentes pressões sobre o meio natural, justificaram a criação de duas unidades de conservação federais: Parque Nacional da Serra do Cipó e Área de Proteção 
Ambiental Morro da Pedreira, essa última, criada no entorno direto do parque, com o objetivo de minimizar as pressões aí incidentes. A criação dessas áreas protegidas conferiu visibilidade nacional à região, intensificando assim, a presença de forasteiros, sobretudo, pesquisadores e visitantes.

Nesse contexto, diversos pesquisadores tem se dedicado a melhor compreender essas mudanças. Costa et al (2003), por exemplo, realizaram uma pesquisa sobre o processo de urbanização no distrito de Cardeal Mota (atual Serra do Cipó), município de Santana do Riacho. Esse distrito está localizado na vertente oeste da Serra do Cipó, às margens da rodovia MG-010 e a totalidade de seu território é abrangida pela APA Morro da Pedreira, o que pressupõe, em termos legais, a obrigatoriedade da compatibilização de objetivos e estratégias de proteção da natureza e desenvolvimento socioeconômico. Segundo os autores, o potencial paisagístico preservado, a proximidade da região metropolitana de Belo Horizonte (distante daí cerca de 100 quilômetros), a facilidade de acesso e o fato de a única portaria do Parque Nacional da Serra do Cipó estar situada nesse distrito foram responsáveis pela sustentação do crescimento do ecoturismo e incremento da expansão imobiliária, associada à fuga, para segundas residências e sítios de recreio, de parcela da população metropolitana de Belo Horizonte. Essas pessoas se dirigem para o distrito da Serra do Cipó em busca "da fuga do cotidiano urbano e do reencontro com a natureza, expressada pelo meio físico. Este processo movimenta e acumula rendas e problemas, mesmo em regiões aparentemente distantes de um cotidiano mais associado à vida urbana" (COSTA et al, 2003, p.99).

Ainda segundo Costa et al (op. cit.), as influências da extensão do urbano presenciadas na Serra do Cipó tem acarretado conflitos associados tanto a interesses divergentes em termos de uso do espaço, quanto a diferenças entre modos de vida mais tradicionais e outros que compõem um enorme espectro, mais típicos das grandes áreas urbanas, aí incluindo-se tanto os turistas/ecologistas/ pesquisadores, quanto os praticantes de um turismo de massa. Para se ter uma ideia, no ano 2000, a população do distrito da Serra do Cipó era de 1.941 habitantes
(IBGE, 2001), mas em feriados prolongados e períodos de férias, a população visitante pode chegar a 30.000 pessoas. Além disso, é possível apontar o aumento crescente do interesse pela visitação de áreas naturais protegidas. De acordo com dados divulgados em 2014, pelo Instituto Estadual de Florestas de Minas Gerais (IEF/MG) e Instituto Chico Mendes de Conservação da Biodiversidade (ICMBio), o Parque Nacional da Serra do Cipó teve aumento do número de visitantes, de 22,3 mil, em 2012, para 25 mil, em 2013, em sua maioria, provenientes da região metropolitana de Belo Horizonte.

Evidentemente, o ingresso aí desse expressivo número de pessoas estimula a economia local, abre espaço para o empreendimento de novos negócios, gera rendas e oportunidades de emprego e trabalhos temporários. Ao mesmo tempo, verificase também um acirramento dos problemas urbanos e socioambientais, como apontam Costa et al (2003): questão fundiária associada à especulação imobiliária; o lixo gerado e dissipado pelo local sem passar por beneficiamento seletivo antes da destinação final; a deficiência de uma rede de esgoto com tratamento dos efluentes líquidos; a carência de fiscalização pública para acompanhar as hospedarias e áreas de camping que abrigam em épocas festivas mais turistas do que o suportado, entre outros. Fica evidente, portanto, a crescente influência da extensão do urbano para muitas regiões localizadas nas proximidades de áreas metropolitanas e grandes cidades, como é o caso do distrito da Serra do Cipó. Nessa região, a presença de unidades de conservação representa um elemento complexificador, seja pela interferência no aumento da atratividade, na agregação de valor à composição de novos produtos imobiliários, seja nos conflitos de uso que emergem em virtude do cumprimento das normatizações ambientais existentes.

Outra experiência que corrobora tais interpretações é a pesquisa realizada por Euclydes (2012), que se dedicou à compreensão dos papéis desejados/exercidos pelas áreas protegidas na produção do espaço no chamado Eixo Sul da Região Metropolitana de Belo Horizonte (RMBH). Essa área constitui foco do choque entre a expansão do tecido urbano da metrópole mineira e a explosão da mineração no Quadrilátero Ferrífero (província 
mineral clássica, situada no centro do Estado de Minas Gerais, onde afloram rochas pré-cambrianas do Supergrupo Minas e onde se localizam jazidas de minério de ferro [itabiritos], manganês, alumínio, ouro, etc.), cujos desdobramentos foram responsáveis por ressignificar os papéis atribuídos às áreas protegidas no eixo sul da RMBH. O debate em torno da conservação da biodiversidade, em um contexto de forte extensão das condições urbanas, revelou conflitos entre diferentes usos capitalistas do espaço, alicerçado numa complexa disputa classificatória pela representação legítima da natureza e pela distribuição de poder sobre a região. Segundo a autora (EUCLYDES, 2012), as áreas protegidas são vistas/desejadas, ao mesmo tempo, como:

- Refúgios para a biodiversidade e entraves à produção e continuidade da realização da vocação mineral do Estado de Minas Gerais;

- Reservas das novas raridades (tanto naturais quanto culturais, referentes aos modos de vida tradicionais);

- Contraprojetos para evitar usos indesejados;

- "Barreiras ao desenvolvimento";

- Mecanismos de modernização ecológica para garantir investimentos internacionais e garantir a expansão das atividades;

- Instrumentos que referendam a preocupação das empresas com a responsabilidade socioambiental;

- Fontes de arrecadação de ICMS Ecológico para as prefeituras;

- Unidades de consolação (termo cunhado pela autora), uma vez que as áreas protegidas desempenham, nesse caso, a função de "acalmar" ânimos ambientalistas;

- Instrumentos de marketing e agregação de valor a produtos, especialmente loteamentos imobiliários;

- Contrapartida para a continuidade da ação das mineradoras, e;

- "Artigos de luxo", demandados por segmentos sociais de alta renda.

É possível perceber, nesse exemplo, que a proximidade com a metrópole mineira constitui um elemento que complexifica o debate sobre a proteção da natureza, ao revelar diferentes interesses e interpretações sobre o papel ou a representatividade das áreas protegidas. Para Euclydes (2012), esses significados convergem e se confrontam segundo o poder dos atores em jogo e os caminhos da discussão, sendo sua competência argumentativa fundamental para definir sua legitimidade, que, por sua vez, repercute diretamente em sua capacidade de interferir na distribuição de poder sobre o espaço e seus recursos. As relações de poder circunscritas nesses territórios expressam, nesse sentido, um caráter de multidimensionalidade (numa visão foucaultiana), o que sugere a superação de visões que acabam reconhecendo ou priorizando apenas o poder institucionalizado do Estado, numa alusão à clássica interpretação ratzeliana de território. Pois, ao contrário, na atual realidade da grande maioria das áreas protegidas, cada segmento ou sujeito social se faz presente no campo de poder mobilizando-se em prol da legitimação de sua visão de natureza, representativa de seus interesses e de suas práticas ou intenções do processo de ordenamento territorial.

Portanto, não se pode desconsiderar que a dinâmica dos territórios dedicados à proteção da natureza é, cada vez mais, permeada pela fluidez, pela multiescalaridade e pelo movimento, estando sob a influência de um conjunto múltiplo de forças e interesses. Em grande medida, como discutimos a pouco, esse contexto se complexifica em virtude da proximidade dessas áreas de centros urbanos e das respectivas condicionantes e transformações associadas. Nessa direção, alguns questionamentos parecem pertinentes: que caminho priorizar no sentido de melhor compreender essa recente complexificação da dinâmica socioespacial intrínseca aos territórios protegidos? Como lidar com essa diversidade de forças e com esses novos condicionantes que se apresentam frente à extensão das condições e modos de vida urbanos? A tradicional visão de ordenamento territorial, alicerçada no poder centralizado do Estado, responde, suficientemente, a esses novos desafios? E nesse contexto, é possível se encontrar estratégias capazes de conferir maior visibilidade a diferentes territorialidades e fortalecer os contraprojetos políticos de seus protagonistas? 


\section{Algumas considerações sobre os novos desafios ao ordenamento de territórios protegidos}

Ao refletir sobre os desafios que se apresentam ao ordenamento de territórios dedicados à proteção da natureza, cada vez mais permeados por contraditórios significados, interesses e demandas em relação ao uso do solo e dos atributos naturais, nos perguntamos sobre que caminhos seguir no sentido de melhor compreender os novos condicionantes e transformações que se impõem à dinâmica socioespacial das áreas protegidas, especialmente daquelas que se encontram na "zona ampliada" de grandes centros urbanos e, por isso, são mais diretamente influenciadas por suas dinâmicas.

Um primeiro aspecto a ser considerado aí, a nosso ver, implica em atentar para um necessário redimensionamento ou reposicionamento dos estudos sobre território e territorialidade(s), não mais estritamente vinculados à fixidez, ao monopólio do poder por parte do Estado e ao fechamento ao exterior, elementos fundantes das primeiras interpretações desses conceitos. Compreender e debater território e territorialidades exige agora, um olhar também voltado a novos referenciais espaciais, ao movimento e aos diferentes e múltiplos arranjos territoriais que passam a caracterizar e moldar o agir e o viver territorial dos diversos sujeitos sociais aí presentes/atuantes. Os territórios passam a ser permeados por novas forças, consequentemente, novos interesses e estratégias de ação que, cada vez mais, se interconectam por e se fundamentam em redes, numa perspectiva multiescalar, relativizando os sentidos até então cristalizados de fronteiras e de limites.

Quando consideramos a temática das áreas protegidas, é possível reconhecer que o conceito de território está na essência dessa concepção de ordenamento do Estado, uma vez que sua criação implica, concretamente, a formação de um novo território por meio de decreto legal. Esta ordem de proteção está ancorada em uma concepção singular de espaço e em mecanismos concretos de intervenção territorial, caracterizados pela delimitação e controle de realidades socioespaciais estratégicas sob o ponto de vista da conservação da biodiversidade. Como resultado, verifica-se a sobreposição de diferentes territórios e exercícios de territorialidade - inclusive exteriores - sob um mesmo recorte espacial, responsável por motivar o surgimento de mudanças sociais e conflitos diversos que, em último caso, amplificam os propósitos de proteção da natureza e desenvolvimento socioambiental.

Diante dessa interpretação, reconhecemos na abordagem territorial um caminho viável de investigação, uma vez que esse método pressupõe o estudo e compreensão, numa perspectiva processual, do movimento, relações, ritmos, conflitos, redes e processos identitários imbricados num dado recorte espacial. A leitura territorial sugere, de fato, segundo Saquet (2007), um olhar processual, relacional, que abrange as des-continuidades, temporalidades, escalaridades e processos históricos da dinâmica territorial, considerando as articulações/interações internas e externas existentes entre as dimensões sociais do território (economia, política e cultura), em unidade entre si e com a natureza. O principal desafio reside, portanto, em dar conta de apreender o movimento nos estudos territoriais, como produto de determinações (i)materiais, de forças econômicas, políticas e culturais em unidade e em saltos quantiqualitativos na dinâmica socioespacial.

Quando adotamos tal caminho teóricometodológico na concretização de pesquisas sobre ordenamento territorial e áreas protegidas, vislumbramos, a propósito, a possibilidade de romper com análises parciais e fragmentadas, que insistem em priorizar temas de investigação ora voltados para "dentro" do território - tratando particularmente de elementos como gestão, conflitos, turismo ou impactos sobre modos devida local-, ora direcionados para olhares muito distantes das realidades das áreas protegidas, mais diretamente voltados ao discurso e interesses oficiais (por exemplo, estudos sobre políticas, programas e ações do poder público), com elevado grau de abstração.

Isso é que nos levou a refletir sobre as áreas protegidas numa perspectiva mais abrangente, processual e multiescalar, a partir das possíveis conexões que elas estabelecem com outros territórios, inclusive centros urbanos localizados em sua proximidade, seja pela presença/atuação cada 
vez maior de diferentes sujeitos/forças externas, como ONGs, pesquisadores e empresários, seja pelo estabelecimento de metas de conservação (definidos em escalas internacional, nacional e regional) e novos direcionamentos de políticas públicas federais e estaduais que são responsáveis por reconformar a dinâmica de territórios permeados por áreas protegidas. Foi aí que atentamos para o tema em debate neste trabalho: as relações estabelecidas e constantemente ressignificadas, desses territórios, com os ambientes urbanos. O reconhecimento dessas novas condições, cada vez mais intimamente relacionadas aos territórios protegidos, sugere novos caminhos e olhares de investigação e nos inspira a debater, no caso brasileiro, sobre estratégias inovadoras capazes de lidar, em termos práticos, com tais transformações. Reconhecendo a impossibilidade de se esgotar tal discussão neste breve ensaio, gostaríamos de chamar a atenção para uma estratégia em particular: a interpretação das áreas protegidas a partir dos enfoques regional e local/territorial.

Como já mencionamos, os territórios de áreas protegidas são influenciados hoje, por um conjunto de questões e dimensões da realidade - regularização fundiária, extrativismo vegetal, impactos associados à especulação imobiliária, construções irregulares e atividades econômicas como turismo, mineração, ações de educação ambiental, desenvolvimento rural, populações tradicionais, entre outras -, que extrapolam os objetivos especificamente relacionados à conservação da biodiversidade. Além disso, a representatividade ambiental, política e econômica das áreas protegidas e o fato de seus territórios abrangerem, em muitas situações, vários municípios, amplifica os desafios ao cumprimento de seus objetivos de proteção e desenvolvimento socioambiental. Nesse sentido, pensar o ordenamento desses territórios exige, também, a adoção de posturas mais integradas e transversais de planejamento e gestão, tanto no contexto local, quanto regional. Isso passa pelo reconhecimento e por uma aproximação com outras instituições e esferas decisórias que compartilham o compromisso de proteção da natureza e desenvolvimento regional, com vistas à construção e implementação de políticas interssetoriais, num esforço de compartilhamento de responsabilidades e de divisão de tarefas.

A articulação interinstitucional e interssetorial representa, contudo, um grande desafio, em virtude da diversidade de órgãos aí envolvidos, multiescalaridade dos espaços de gestão e decisão e, também, da multiplicidade de políticas e programas setoriais que precisam ser concebidos e trabalhados, idealmente, de maneira integrada e transversal. Quando consideramos apenas a dimensão ambiental, já reconhecemos uma enorme dificuldade de atuação conjunta e coordenada entre as diferentes instâncias de gestão. Quando inserimos neste debate outros temas e realidades como uso e ocupação do solo, urbanização, turismo, infraestrutura, mineração, produção rural, agricultura familiar, apenas para citar alguns, percebemos uma dificuldade ainda maior de integração e transversalidade de ações.

Já a esfera territorial/local diz respeito mais diretamente às múltiplas relações de poder que conformam os territórios permeados pelas áreas protegidas e, sobre os quais, se impõem os desafios de conservação e desenvolvimento socioambiental. É relevante assinalar que a dimensão territorial exige um olhar para o conjunto de forças políticas, econômicas e simbólico-culturais presentes e atuantes em determinado recorte, a partir de uma perspectiva de governança que privilegie processos participativos e descentralizados de gestão e decisão, mais próximos dos cidadãos e, portanto, mais próximos também das demandas e interesses aí incidentes.

Vale ressaltar que essa perspectiva territorial da governança sugere a superação da ótica dos limites politico-administrativos dos municípios, para privilegiar uma lógica que pressupunha o envolvimento de territórios e territorialidades contíguos a partir de laços físicos e, sobretudo, por relações históricas e contemporâneas de significado, vivências socioespaciais e vínculos de pertencimento a um determinado recorte espacial.

É relevante assinalar que essas ideias de contiguidade e integração dependem, em grande medida, da existência de institucionalidades capazes de articular tanto as forças locais como as forças exógenas na definição dos rumos do ordenamento territorial. Trata-se de um elemento central nesse debate, uma vez que as instituições são interpretadas, 
idealmente, enquanto espaço democrático que garante ao cidadão o exercício de seus direitos. Nessas condições, as instituições podem representar uma oportunidade de construção de um contraponto à cultura centralista, à excessiva concentração de poder nas mãos de determinados grupos sociais e, principalmente, figurar enquanto espaço de acesso e exercício de cidadania.

Contudo, a constituição de um arcabouço institucional plural, representativo e integrado passa pelo esforço necessário de estímulo às iniciativas de auto-organização comunitária no território, capaz de conformar uma esfera pública não-estatal, legítima, autônoma e com efetivo envolvimento no âmbito dos processos decisórios acerca do desenvolvimento territorial. Tal questão se apresenta como essencial já que é justamente nesses espaços com alto viés democrático onde poderão ser congregados os principais temas e questões comuns à realidade dos territórios permeados por áreas protegidas, bem como os debates em torno do reconhecimento das principais demandas e da construção de propostas coletivas frente às transformações e novas condicionantes aí vivenciadas.

No caso específico das condicionantes associadas à extensão do modo de vida urbano para além das cidades, a relação cada vez mais intrínseca e interdependente entre áreas protegidas e ambientes urbanos - ideia defendida neste ensaio - exige uma ótica de interpretação que não se limite apenas ao apontamento dos impactos negativos daí decorrentes, num sentido de contestação ou de denúncia. Pois, ao se reconhecer que essa relação é, em grande medida, constituinte dos territórios de muitas áreas protegidas brasileiras, o esforço agora reside em encontrar formas propositivas de lidar com essa nova realidade.

Uma alternativa nessa direção pressupõe que os gestores de áreas protegidas atuem ativamente junto aos poderes públicos de municípios que possuam alguma relação com a área protegida. $\mathrm{O}$ desafio reside em construir parcerias, participar da definição de diretrizes de desenvolvimento municipal e apoiar o empreendimento de projetos e ações que se remetam à conservação da biodiversidade e ao desenvolvimento socioambiental. Esforços no sentido de sensibilizar gestores municipais sobre a importância das prefeituras no gerenciamento dos territórios das áreas protegidas poderia resultar, por exemplo, numa maior integração e alinhamento de ações de planejamento e gestão territorial em curso, contribuindo decisivamente para a construção de processos de governança territorial.

Outra iniciativa envolveria a participação efetiva da chefia e de representantes do conselho gestor da área protegida na elaboração dos planos diretores municipais, bem como nos debates e audiências públicas previstos. Os planos diretores constituem o principal instrumento legal de planejamento e regramento do uso do solo, que preveem, entre outros assuntos, a visão do município em relação à prioridade concedida ao tema da proteção da natureza, bem como às intenções e projetos a eles atrelados. Diante de toda a complexidade que permeia o processo de elaboração dos planos diretores municipais, vale dizer que esses espaços tem representado uma oportunidade de participação social e de construção de compromissos coletivos. Ao mesmo tempo, representam uma oportunidade de reconhecer os diversos e contraditórios interesses aí em jogo e, até que ponto, tais interesses podem acarretar uma ameaça à continuidade dos resultados de proteção alcançados pela área protegida. Nesse caso, identificar essas forças e intenções sobre o território constitui condição essencial para que os gestores tenham condições de articular propostas de interesse coletivo e fortalecer estratégias capazes de frear projetos que levem a grandes interferências nos exercícios de territorialidade e no grau de proteção dos atributos naturais. Vale ressaltar ainda que a participação nos diferentes conselhos e instâncias de gestão existentes no contexto territorial da área protegida (conselhos municipais de meio ambiente, saúde, saneamento, turismo, cultura, comitês de bacia hidrográfica, entre outros) constitui mais um meio eficaz de se aproximar da complexidade de temas caros ao território e, sobretudo, promover diálogos e edificar acordos que levem à transversalidade na gestão e planejamento territorial.

Outro aspecto relevante nessa discussão é que a proximidade de centros urbanos pode estimular a atuação em rede, possibilitando aos diferentes sujeitos e representatividades sociais a 
oportunidade de construir parcerias para a realização diversas iniciativas, bem como o acesso a experiências inovadoras - práticas, tecnologias sociais, processos de gestão, entre outros - que podem auxiliar sobremaneira na construção de novos projetos em diferentes áreas. Monte-Mór (1994) enfatiza que, apesar do caráter unificador e das pressões sobre os territórios de fronteira, o movimento de urbanização extensiva pode contribuir para que esses grupos sociais encontrem formas de resistir e dar sentido e concretude aos seus projetos políticos, assumindo um papel de sujeitos nesse campo de disputas. Ao mesmo tempo, dá visibilidade a novas territorialidades e estimula o comprometimento social, a construção de relações de confiança e o aproveitamento das capacidades e valores locais na busca por soluções aos problemas existentes e na definição dos rumos do processo de desenvolvimento almejado. O desafio que se apresenta, segundo esse autor, é se encontrar novas formas de integração entre centros urbanosmetropolitanos e o hinterland rural-região, sobretudo se o objetivo for se buscar o aprimoramento das formas de ocupação e produção do espaço social.

Nesse sentido, o debate atual sobre ordenamento territorial e áreas protegidas passa pelo reconhecimento de que essa dinâmica está cada vez mais intrinsecamente relacionada aos territórios dedicados à proteção da natureza e que os esforços no sentido de se alcançar os objetivos de conservação da biodiversidade e promoção de desenvolvimento territorial dependem, decisivamente, da capacidade de entendimento e equacionamento das ameaças e oportunidades associadas à extensão das condições e modos de vida urbanos para além das metrópoles.

\section{REFERÊNCIAS}

BETARELLI JUNIOR, A. Urbanização extensiva e o processo de interiorização do Estado de São Paulo: um enfoque contemporâneo / Admir Antônio Betarelli Junior, Roberto Luís de Melo Monte- Mór, Rodrigo Ferreira Simões. - Belo Horizonte : UFMG/ CEDEPLAR, 2013.

BRYANT, R. e BAILEY, S. A politicized environment. Third World Political Ecology. Routledge: London and New York, 1997.
CHAMBERS, S. A critical theory of civil society. In: CHAMBERS, S. \& KYMLICKA, W. (eds.). Alternative conceptions of civil society. Princeton: Princeton University Press, 2002.

COSTA, H.; OLIVEIRA, A.; RAMOS, M. População, Turismo e Urbanização: Conflitos no Uso e Gestão Ambiental. GEOgrapkia -Ano V - No 10 - 2003.

DIEGUES, A. C. O Mito Moderno da Natureza Intocada. São Paulo: EDUSP, 1994.

EUCLYDES, A. C. Proteção da natureza e produção da natureza. Política, ideologias e diversidade na criação de unidades de conservação na periferia sul da metrópole belo-horizontina. Dissertação de Mestrado. Programa de Pós-Graduação em Geografia, UFMG, 2012.

HAESBAERT, R. Concepções de Território para entender a desterritorialização. In: SANTOS, Milton e BECKER, Bertha. (orgs.) Território, Territórios: ensaios sobre o ordenamento territorial. Rio de Janeiro, DP\&A, 2a edição, 2006.

HARVEY, D. Condição pós-moderna. Uma pesquisa sobre as origens da mudança cultural. São Paulo: Loyola, 1993 [1989].

HARVEY, D. Limits to Capital. Oxford, Basil Blackwell and Chicago, University of Chicago Press, 1982.

LEFEBVRE, H. La Production de l'Espace. Paris: Anthropos, 1986.

MEDEIROS, R. A proteção da natureza: das estratégias internacionais e nacionais às demandas locais. Rio de Janeiro: UFRJ/PPGG, 2003. 391p. Tese (Doutorado em Geografia).

MONTE-MÓR, R. L. As teorias urbanas e o planejamento urbano no Brasil. In: DINIZ, \& CROCCO (Eds.). Economia Regional e Urbana: contribuições teóricas recentes. Belo Horizonte: Editora UFMG, 2006. 
MONTE-MÓR, R. L. What is the urban in the contemporary world? Cadernos de Saúde Pública, vol.21 no.3 Rio de Janeiro May/June, 2005. DOI: http:// dx.doi.org/10.1590/S0102-311X2005000300030

MONTE-MÓR, R. L. Urbanização Extensiva e lógicas de povoamento: um olhar ambiental. In: SANTOS, M.; SOUZA, M. A.; SILVEIRA, M.L. (eds.) Território, globalização e fragmentação. São Paulo: Hucitec/Anpur, 1994.

MORAES, A. C. R. \& COSTA, Wanderley M. da. Geografia Crítica: A Valorização do Espaço. São Paulo. Editora: HUCITEC, 1984.

ROBERTSON, R. Globalization: Social Theory and Clobal Culture, Londres, Sage, 1992.

SAQUET, M. Abordagens e concepções de território. São Paulo: Expressão Popular, 2007.

SOJA, E. Postmetrópolis. Estudios críticos sobre las ciudades y las regiones. Madrid, 2008.

TONUCCI FILHO, J. Cidade Fractal: Transformações Recentes na Região Metropolitana de Belo Horizonte. In. XIII Encontro da Associação Nacional de PósGraduação e Pesquisa em Planejamento Urbano e Regional. 25 a 29 de maio de 2009. Florianópolis, SC, Brasil. 